\title{
Analysing Interlanguage Stages ALEs Pass through in the Acquisition of the Simple Past Tense
}

\author{
Anwar Mourssi ${ }^{1}$ \\ ${ }^{1}$ Faculty of Arts, Creative Industries and Education, University of the West of England, Bristol, UK \\ Correspondence: Anwar Mohammed Abdou Mourssi, P. O Box 546, P. C. 115 Madinat Qaboos, Muscat, \\ Sultanate of Oman. Tel: 968-9975-2788. E-mail: anwarmohd1967@yahoo.com
}

Received: July 10, 2012 Accepted: July 25, 2012 Online Published: August 23, 2012

doi:10.5539/elt.v5n10p148 URL: http://dx.doi.org/10.5539/elt.v5n10p148

\begin{abstract}
Building on previous studies of cross-linguistic influence (CLI) on SLA, and principled criteria for confirming its existence in L2 data, an empirical study was run on 74 Arab learners of English (ALEs). A detailed analysis was made of Interlanguage stages of the simple past tense forms in 222 written texts produced by ALEs in the classroom settings.

Written texts were collected from each subject at 3 stages in the experiment (after 2 weeks, 2 months and 4 months). The analysis of the non-target-like forms indicated that interlanguage stages do not appear in isolation.

Quantitative and qualitative analysis in addition to descriptive analysis indicated seven interlanguage stages that ALEs may go through in the acquisition of the simple past. The stages will be presented and detailed examples will be given of the way in which the non-target-like forms were categorized.
\end{abstract}

Keywords: language acquisition, interlanguage, crosslinguistic influence, simple past

\section{Introduction and Hypotheses}

The purpose of the study is to focus on the students' interlanguage grammar with respect to the acquisition of the simple past tense and hopes to contribute to our knowledge in this area. What stages of Interlanguage grammar do Arab Learners of English (ALEs) go through in the acquisition of the simple past tense? Based on the shortcomings found in previous methods of teaching and following recent works in applied linguistics on form-focused instruction, explicit teaching and learning, and types of feedback, my hypothesis has three dimensions.

The first dimension is that the acquisition of the simple past tense in English can be rapidly achieved by explicit grammar teaching which seems to be effective with both low and high level second language learners.

The second dimension is that drawing second language learners' attention to their non-target-like simple past forms, focusing on form, and receiving metalinguistic feedback in a form of contrastive/error analysis, recasting or some form of corrective feedback, creates a space for interactions among interlocutors. This in turn leads to drawing the second language learners' attention to the gap between the simple past forms they want to write and the forms they can actually write. This process, I claim, results in second language learners progressing more rapidly through the interlanguage stages than those who are not exposed to such a process.

The third dimension is that, when second language learners practise the target-like forms of the simple past instead of their non-target-like simple past forms, this practice improves their performance by proceduralzing their implicit knowledge. This raises their consciousness, increases their competence and helps them produce the target-like language forms. When learners practise the target-like forms, they will pay attention to their performance. Paying attention in the learning process will activate their implicit knowledge. At the same time "consciousness raising" requires an effort on the learners' part: they have to understand the target features of the target-like forms of the simple past tense and they do this through explicit grammar learning. This leads us to hypothesize that "consciousness raising" may improve explicit knowledge of the L2, while practice may enhance the implicit knowledge of second language learners. The objective of the current study is to determine the interlanguage stages that can be found in the acquisition of the simple past tense by Arab learners of English. The research question and methods used are presented in the following part. 


\section{The Research Subjects}

Two classes were selected from a total of 12 classes enrolled in grade 12. The target location was in one of the Omani government secondary schools (High School). Each group consisted of 37 Arab Learners of English ALEs, with ages ranging between 16 and 18. They are pre-intermediate to intermediate level in English. The subjects were all Arabic speakers and had been learning English as a foreign language for eight years attending 4 to 5 sessions per week on average. Their studies were based on the course book entitled "Our World Through English" OWTE course book.

\section{Literature Review}

\section{The Context of Arab Learners of English and Acquiring Grammar}

This section consists of four sub-sections. First in 3.1, I will present the importance of grammar in learning the L1 and its impact on learning the L2. In 3.2, I will present the acquisition of the simple past. Third, in 3.3, I will present the development interlanguage stages in the acquisition of the simple past. Finally in 3.4 , I will present ALEs and using regular and irregular simple past forms.

\subsection{The Importance of Grammar in Learning L1 and Its Impact on Learning L2}

Prescriptive Arabic grammarians think that grammar is the only element which shows how language is used. They also view the traditional grammar of any language as a set of rules, and the major concept in learning language is to learn its grammar first. According to them, the most common and appropriate learning strategy of learning is memorization, which is reflected in the way they learn L2. They think that memorization helps learners to achieve the tasks required in learning the target language better than any other strategy. This affects the methods of teaching followed by teachers of English for Arab learners who try to achieve the objectives of the target task in a proper and a suitable way which matches learners' attitudes. Similarly, it affects the way Arab learners of English acquire a second language in general and second language grammar in particular. This view is also reflected in the SLA research done based on samples taken from Arabic speakers of English.

Learning English (as an L1 or L2), grammar can be viewed in different ways. Hymes (1972) states, English speakers need to know the rules of grammar with the rules of language use in order to communicate in a language. Dickins \& Woods (1988) believe that the role of grammar is to convey and interpret meanings (p.630). While Fuller \& Gundel (1987) suggest that grammatical rules (patterns that are studied by syntacticians and morphologists) were basically designed to help people get their meaning across clearly and accurately (p.70).

Furthermore, a number of linguists claim that grammar is essential for appropriate communication. Lock (1996) posits that language is a resource for communication and claims that grammar lies at the heart of communication and is not an optional add-on to communication (p.267). Similarly, Leech \& Svartvik (1982) view grammar as the focal part of language which relates to phonology and to semantics as well (p.4). Harmer (1991) believes that knowledge of grammar is essential for competent users of a language (p.23). Larsen-Freeman and Long (1991) asserted that grammar is one of three interconnected dimensions of language which include: grammar, semantics and pragmatics.

Similar to the perspectives offered by Arab language grammarians, Klein (1986) postulates that in order to learn a foreign language, learners should have the ability to analyse the linguistic input in the target language. More recently, Gao (2001) describes grammar as a catalyst for second language accuracy and fluency (p.326).

Ismail (2010) demonstrates that Arab learners of English had positive views about the use of the CCCC grammar model, which is presented in four stages: Confrontation, Clarification, Conformation, and Consolidation. The author also highlighted certain students' beliefs about the importance and the positive influence of explicit grammar teaching for learning the conventions of sentences and utterances (p.143).

\subsection{Acquiring the Simple Past Tense}

Quirk, Greenbaum, Leech \& Svartvik. (1985) point out that the simple past tense indicates that something happened at a specific moment in the past. In conformity with the simple present, the simple past contains three different meanings; the "event past", the "state past", and the "habitual past". Referring to a single and specific action in the past is the "event past". The "state past" is used when the verb's meaning is a statement, while the "habitual past" concerns those verbs which refer to a repetition of an action (p.186).

On one hand, learning the past tense has been the subject of debate in cognitive science since Rumelhart \& McClelland (1986) first modelled it as part of their parallel distributed processing effort. In the same vein, a number of researchers have contributed to the issue since, criticizing the original model (e.g. Pinker \& Prince, 1988) or offering alternatives, either connectionist, such as: MacWhinney \& Leinbach, (1991); Plunkett \& Juola, 
(1999); Plunkett \& Marchman, (1991,1993), or symbolic, such as Ling \& Marinov, (1993). A substantial amount of information has been gathered about the use of past tense verbal morphology in a variety of languages, such as Andersen, 1986, Bardovi-Harlig \& Reynolds, (1995); Salaberry, (2003), and Salaberry \& Shirai, (2002).

Forming the simple past in English is considered one of the most difficult problems facing ALEs while learning English grammar. Comparing Arabic with English, we find that Arabic does not have regular and irregular verbs, which causes a plethora of non-target-like forms produced by ALEs while acquiring the simple past in English. Brown (1998) claims that irregular verbs are more complicated and cause many difficulties for language learners, and many of them are still poor in understanding irregular forms even those in universities (p.142). Based on my experience in teaching ALEs for many years, it is concluded that the performance on the irregular verbs dipped after acquiring the -ed rule; this causes what is termed U-shaped behaviour. Another problem facing ALEs is the English verbs which can be regular and irregular at the same time, for example:

Hang, hanged, hanged (to kill or die, by dropping with a rope around the neck), and

Hang, hung, hung (to fix something-a picture- at the top so that the lower part is free)

Based on what is mentioned above, it is decided to select the topic of the study to investigate how ALEs acquire the simple past in English, to compare and contrast the current study with the previous studies in different contexts. Besides, I think that ALEs may have different interlanguage stages in acquiring the simple past.

\subsection{Development Interlanguage Stages in Acquiring the Simple Past Tense in English}

Pienemann (2005) applies processability theory to explain the sequence found in the second language acquisition of English. He focuses on the development of two areas: In the area of morphology, he investigates plural marking on nouns, possessive pronouns, and S-V agreement marking, in the area of syntax, he concentrates on word order. He does not investigate the sequential development of acquiring the simple past tense in English (p.19).

In investigating tense continuity in narrative writing, Frawley \& Lantolf (1985) observe that it is well-known that events in narrative writing are related to the historical present by native speakers. In other words, past tense usage is not obligatory in this type of discourse. They add that L2 beginners do not typically make use of tense distinctions, preferring other devices to realize temporal relationship between events. Ellis (1987a) comments that these observations are potentially problematic for a study seeking to investigate the use of past tense forms in narrative writing. This may explain the frequency of the use of the root and the simple present by the subjects in the current study, although the subjects were informed to use the simple past tense forms in performing the writing task.

In another empirical study measuring order of accuracy, Ellis (1987a) investigates interlanguage variability in narrative discourse. He examines style shifting in the use of three past tense morphemes (regular past, irregular past, and past copula) by 17 intermediate L2 learners of English. The data were collected under three conditions: the first condition was planned writing, the second condition was planned speech, and the third condition was unplanned speech. The three conditions produced different accuracy orders for regular and irregular past, suggesting that the so-called "natural order" may not be a stable phenomenon. Ellis (1987a) suggests that there is evidence to show that second language learners perform variably on different tasks. He concludes that the accuracy of interlanguage morphology in L2 learners' narrative discourse differs according to the amount of planning time available. He found that the accuracy orders for the three past tense forms varied, in other words, the regular past had the highest accuracy score in the writing task (planned writing), while in task two (planned speech) regular past verbs scored lower than the copula and about the same as irregular past, and in task three (unplanned speech) the regular past scored the lowest of all the other past tense forms by a wide margin. So I think that ALEs will have a different sequence of interlanguage behaviour in acquiring the simple past tense in English from learners of other L1 backgrounds.

In investigating the Text-type and the Task-type variables in acquiring simple past, Vet and Vetters (1994, p. 1) claim that the meaning of tense and aspect forms "strongly depends on contextual factors and probably on the type of text as well." Similarly, Hopper (1982) argues that the nature of aspectual distinctions in a language like Spanish cannot be characterized by semantics in a consistent way; the adequate reference may come from a global discourse function (p.16). This justifies Bardovi-Harlig (1998) when she claims that "text-type" should be an important variable for the analysis of inflectional morphology in L2 acquisition studies.

In a well-known classification of verbs from a lexical point of view, Vendler (1967) proposed that verbs can be grouped into four types, according to their inherent aspect, examples after Salaberry (1999): 
Statives (e.g. to be, to have, to want)

Activities (e.g. to run, to walk, to breathe)

Accomplishments (e.g. to write a novel, to build a house)

Achievements (e.g. to notice someone, to realize something, to reach the summit)

It is worth mentioning that the current study focuses on how to improve second language learners' written accuracy following picture-story writing in which ALEs use only activity verbs.

Drawing on the European Science Foundation and other studies, Bardovi-Harlig (2000) concludes that interlanguage users of any language in a classroom context will pass through three successive stages when talking about time: a pragmatic stage, a lexical stage, and a morphological stage. According to Bardovi-Harlig (2000) and others, learners enter the morphological stage, once examples of tense-aspect morphology are noted in their Interlanguage utterances. This is termed as the "emergence" of morphology, and does not necessarily mean that the forms produced by learners are used accurately and consistently. Bardovi-Harlig (2000, p.111) lists four general principles that have been found in studies of the emergence of verb morphology: in the third stage, she mentions that irregular morphology precedes regular morphology (e.g. went, came appear ahead of forms such as jumped, ended).

In an empirical study investigating the development of past tense verbal morphology in learning Spanish as an L2, Salaberry (2003) concludes that learners of Spanish may use a default marker of past tense during the beginning stages of development of verbal morphology, but the default option may be dependent on the type of text, whether it is personal or fictional.

One of the latest studies which investigates how various features of the input-frequency distributions, reliabilities of form-function mapping, and prototypicality of lexical aspect-affect tense and aspect morphology was carried by Wulff, N. Ellis, Romer, Bardovi-harlig \& LeBlanc. (2009). Their study reports the results of two corpus-based studies: the first study determined the relative frequency profiles of exemplars of English tense and aspect and employed various statistics to determine the associations between particular verb-aspect combinations; the second study expanded the aspect hypothesis. They examined whether native speakers judge the most frequent forms in isolation to be more prototypical in lexical meaning.

Previous literature on second language acquisition of the simple past tense in English suggests that the accuracy order of two simple past tense forms (irregular past tense and regular past tense) varied depending on how the data were collected. Ellis \& Barkhuizen (2005) added that in the case of careful written production, the regular past tense was more accurate but in the case of spontaneous production it proved less accurate than the irregular form. This appears to concur with Ellis' (1987a) findings. In general the order of acquisition of different grammatical structures can vary according to the kind of task used to elicit samples of learner language, (Ellis \& Barkhuizen, 2005, p.220).

Meisel (1987) and a number of researchers observed the developing ability to use language to locate events in past time. He mentions that second language learners from different first language backgrounds acquire the language for referring to past events in similar patterns. These patterns are described as follow:

Stage one, where learners with limited language use the base form or the simple present to show the event occurred in the past.

My son come. He work in a restaurant.

\section{Viet Nam. We work too hard.}

Stage two, where learners start to attach a grammatical morpheme marking -ing for simple past tense.

Me working a long time. Now stop.

Stage three, where learners use irregular verbs before regular verbs.

We went to school every day. We spoke Spanish.

Stage four, where learners overgeneralize the regular - ed to irregular verbs, and use present perfect instead of simple past.

My sister catched a big fish.

She has lived here.

McDonough (2007) coded learners' activity verbs in past time contexts in terms of their grammatical forms as simple past morphology supplied or absent. He classified the subjects' errors in the formation of simple past 
tense morphology as: overgeneralization, where learners overgeneralize regular past tense rule $-e d$ to irregular verbs such as: telled, gived, writed as morphology supplied. Other past forms such as past progressive and past perfect were not included in the analysis, which was focused on the learners' production of simple past forms only. One of the results of McDonough's (2007) study is that in all the groups of his study -no feedback group (student did not receive any type of feedback), clarification request group, and recast group (recast means a corrective reformulations of learners' utterances. It draws the learners' attention to the mismatches between input and output, that is, causes them to focus on form and induce noticing of the kinds of non-target-like forms) tended to use simple present and base forms with their past time activity verbs and rarely produced progressive forms.

Some other studies have discussed the accuracy order for the morphemes in relation to the interlanguage stages in acquiring simple past tense in English, Lightbown and Spada (2006) mention that the accuracy order cannot be described or explained in terms of transfer from the learners' first language, however, a thorough review of all the morpheme acquisition studies shows that the learners' $L 1$ does have an influence on acquisition sequences. They also mention that some of the errors of second language learners are remarkably similar to errors of young first language learners for example, the use of a regular -ed past tense ending on an irregular verb e.g. goed, catched (p.83).

In a classroom setting study, Housen (1995) observed, over a three-year period, six learners of L2 English whose native language was French and Dutch. Housen's results were mixed: the French learners were overall less proficient than the Dutch learners and never reached the stages where they could use past morphology productively. Transfer factors were also involved specifically in the case of the past/non-past distinction, where Dutch is closer to English.

Collins (2002) shows that the first language can have an influence in acquiring the L2. Collins (2002) investigates the different English verb forms used by French speakers. Collins (2002) observes that in places where English speakers would have used simple past, French speakers did sometimes use the present perfect or the past perfect instead of the simple past (p.85). In the context of Arab learners of English, learners will use was or were + root, simple past, agent, past participle or gerund. That is because in Arabic narrating stories, they use the verb كان "Kanna" before the stem, agent or other forms of the verb. كان "Kanna" in Arabic equals was, were in English.

In the current study, I do not investigate the lexical aspect of the verbs produced by the subjects of the study as most verbs produced were activities verbs.

Lightbown and Spada (2006) mention that sometimes language acquisition is reflected in a decrease in the use of a correct form that was based on rote memorization or chunk learning. They add that an increase in error may be an indication of progress, mentioning that like first language learners, second language learners usually learn the irregular past tense forms before they learn to apply the regular simple past -ed marker (p.77). Lightbown and Spada (2006) mention that the progress achieved in the classroom context by second language learners to a higher stage in interlanguage does not always mean that learners produce fewer errors (p.93). In the following, I will talk about ALEs and using regular and irregular simple past tense forms.

\subsection{Arab Learners Learning and Using Regular and Irregular Simple Past Forms}

Previous works on the acquisition of the simple past tense in English as an L1 have noted that irregular simple past forms are acquired before regular simple past forms. Brown (1973) presents the following order of language acquisition:

- Present progressive -ing (Mommy running)

- Plural -s (Two books)

- Irregular past forms (Dady went)

- Possessive's (Daddy's hat)

- Copula (Annie is happy)

- Articles the and $a$

- Regular past-ed (She walked)

- Third person singular simple present $-s$ (She runs)

- Auxiliary be (He is coming) 
De Villiers \& De Villiers (1973) also confirmed that children learning English as a first language mastered the morphemes at different ages, but the order of their acquisition was very similar. In other words, irregular simple past forms are acquired before the regular simple past forms. Bardovi-Harlig (2000) concluded that irregular morphology precedes regular morphology in learning English as L2 as well.

Previous studies have investigated the difficulties learners face in learning English simple past forms. McDonald \& Roussel (2010) examined whether problems with English regular and irregular past tense are related to poor L2 phonological ability and lexical access. They conclude that non-syntactic processing difficulties can have a specific impact on morphosynatctic performances in both non-native and native English speakers.

Ramadani (2009) discovered that the most common error students make in using simple past tense is with the structure of question sentences in the simple past tense where the use of regular or irregular verbs generate a different meaning. He also noted that remembering the irregular past tense form is another problem.

Yap \& Alsagoff (2005) investigated errors in past tense marking in Singapore secondary school students' composition. They claim that a learner will acquire an appropriately morphological tense marking for telic verbs (i.e. achievements and accomplishments) before atelic verbs (i.e. states and actives). They mention that the Aspect Hypothesis suggests that the distribution of tense errors can be predicted on the basis of telicity. In their study, they formulate and test the hypothesis that the aspectual classes of verbs can explain patterns of errors in past tense marking. Their data collection consists of the middle of year examination composition scripts from a secondary school to ensure that the outputs from the subjects are not influenced by teachers or peers. Compared with the current study, the output was as a result of the teacher's input in both groups. Findings from their study reveal that the lexical semantic of verbs can account for tense marking errors.

Andersson (2008) investigates what types of errors the students make regarding time and tense in Sweden and, secondly, compares the types of errors made with the results found from 1995 in To Err Is Human (Kohlmyr, 2003). The result shows that most errors occurred in the present tense. As many as 117 errors were found in the present tense whereas 80 errors were found in the past tense, and 66 errors were found in the future tense. The errors made in the past tense are categorized into four groups, namely, the simple past, the present perfect, the past perfect, and the past passive. She found that out of the 80 errors found in the past tense, 50 per cent occurred with the simple past tense. She concludes that the school must start to teach grammar explicitly in order to give the students the chance to use the language in a target-like way in communication.

Previous research studies suggest that beginners level can correctly use irregular verbs, while intermediate level students start using regular and irregular verbs to some extent of target-likeness; at upper intermediate level, students start using both forms in a target-like way, and gradually they master the regular and irregular forms not only in simple past forms but in other aspects in the target language as well. These stages can represent the stages of Interlanguage development on the one hand and the stages of developing the internalised grammatical system on the other in relation to acquiring the simple past tense in English. In the following, I will present the research question and the methods used.

\section{The Research Question and Methods Used}

Based on the literature review and the research objectives, the present study addresses the following question:

Which interlanguage stages can be found in the acquisition of the simple past tense in the ALEs' context?

\subsection{Methods Assigned to Research Question}

The methods assigned for the research question is as follow; the simple past forms in three texts written near the beginning, middle and end of the teaching period were extracted from the samples and analyzed. The first written texts (B) were collected after the initial two weeks; the second written texts (M) were collected after the first two months and the third written texts (F) were collected at the end of the experiment. The experiment covered a total of four months. All the simple past forms produced by ALEs in the three chronological writings were analyzed both quantitatively and qualitatively, on the basis of which it was possible to propose the interlanguage grammar development stages that ALEs go through in the acquisition of the simple past tense, albeit over a fairly short time-scale.

I will discuss the criteria used in categorizing interlanguage development in the acquisition of the simple past tense by ALEs.

\subsection{The Criteria Used in Discussing the Written Samples}

Each occurrence of a simple past tense form in the students' written samples was carefully counted and analyzed. Intuition has been used to allocate examples to different categories. It is noticed that learners use different forms, 
for example: using run instead of ran, and using thanks instead of "thanked". With respect to the distinction between types and tokens in calculating the rates of development in L2 learners' simple past forms, even though goed or wented are non-target-like forms, they show some kind of development in a student's interlanguage grammar. Each form produced by the subjects is discussed and analyzed for the purpose of this study.

Categorizing the forms in sequence interlanguage stages is based on particular categories that were established from the start and were confirmed as the study went along, the categories were also confirmed by calculating all the non-target-like and the target-like forms produced by all the samples of the study.

In the following section I will analyze the interlanguage stages observed in acquiring the simple past tense, as evidenced in the three written samples produced by the learners.

\section{Analysis}

\subsection{Interlanguage Stages in Acquiring the Simple Past Forms in English in the Context of Arab Learners}

After presenting what has been suggested by previous research on the acquisition of the simple past forms, the present study aims, firstly, to test Meisel's (1987) sequential stages established in naturalistic situations against the empirical data collected in classroom contexts. I am using picture stories as part of the investigation to gauge to what extent they hold true of ALEs at pre-intermediate and intermediate stage.

The total number of essays analyzed was 222 , with 74 samples from the experiment. These essays were of about 100 words each. The total amount of simple past tokens for the subjects in three stages was 3087 forms.

All the regular and irregular target-like and non-target-like simple past tense forms were carefully counted in all the stages, to cover all types of interlanguage behaviour which occur in the three stages of the experiment and to get an empirical evidence and consistent results for the study showing how the simple past form is acquired by ALEs and what interlanguage stages they may pass through to correctly acquire the simple past tense forms in English.

In categorizing the learners' non-target-like forms, some non-target-like forms were repeated in different stages. So, it was difficult to make a clear dividing line between one stage and the next. Analyzing all the non-target-like forms produced by all the subjects of the study in both groups, and categorizing the interlanguage stages followed in acquiring the simple past tense, does not mean that these stages can be generalized to all second language learners in acquiring the simple past forms in English, but attempts to cover most of the variety of types of interlanguage behaviour adopted by ALEs while acquiring the simple past tense forms in English. The acquisition of simple past for this detailed study seems to be varied perhaps because Arabic L1 students may be in different stages from the stages investigated by other researchers in different contexts. E.g. using the verb to be with the root or with the simple past form or with the past perfect form (was go, was went, and was caught) can represent one of the characteristics of the interlanguage grammar development followed by ALEs in the acquisition of the simple past tense. I also think that explicit teaching/learning and metalinguistic feedback can help students - ALEs - go through the stages more quickly.

Another issue in categorizing the stages of interlanguage behaviour is that some second language learners produced some non-target-like forms which cannot be grouped into a recognizable category; this is because it is difficult to establish which verbs they are. For example: stoke, colle, arer, dicet, and akrusnt. It was difficult to categorize these forms as performance non-target-like forms such as: showted, brook, trayed, foneshed, and snated which are categorized as stage two in the interlanguage grammar development stages proposed in the acquisition of the simple past tense in the current study. Producing these forms (showted, trayed, snated, finished, and hapenned) can be evidence that the student's internal grammar has taught him/her that you should add -ed to these verbs, and can be evidence that the learner has developed the regular "add -ed" rule. Learners who produced these forms at this stage need to learn the target-like form in learning the simple past tense in English in order to improve their written accuracy.

Following a sub-type of the categorization of some studies such as McDonough (2007), Bardovi-Harlig (1998), and Lardiere (1998), some parts were excluded from the categorization for the purpose of the study. In the current study some of these are caused by interaction outside the classroom context, so it cannot be over-generalized to all the second language learners because not all of them have the chance to interact in L2 outside the classroom context, e.g. scarde, backhome, and tank. Hence, these forms were excluded from the categorization of the interlanguage stages in the acquisition of the simple past tense in the ALEs' context.

In comparing and categorizing all the non-target-like forms produced by all the subjects, each interlanguage stage is tabulated in three sections: the first section represents the non-target-like produced by the subjects in writing $\mathrm{B}$, while the second section represents the non-target-like produced by the subjects in writing $\mathrm{M}$. The 
third section represents the non-target-like produced by the subjects in writing $\mathrm{F}$.

The data is presented from the most to the least commonly occurring non-target-like forms. Percentages given in brackets show the proportion of non-target-like forms attributable to the subjects' production of simple past forms respectively at each of the three writing stages, B, M and F.

Most non-target-like forms in the data could be categorized into seven basic types which are illustrated below, from the most frequent to the least frequent.

\section{Stage One}

The most frequent non-target-like form overall (in productions B, M and F) was the use of the root or the simple present tense form instead of the simple past tense form; students produced 689 non-target-like forms which represents $69.5 \%$ of the total number of non-target-like forms, (e.g. go, come, stay, calls, and help). Table 1 below shows the proportion of forms which represents stage one in the interlanguage development in the acquisition of the simple past tense.

Table 1. The use of the root or simple present form

\begin{tabular}{ll}
\hline Stage & Non-target-like simple past forms \\
\hline B & $328(47.6 \%)$ \\
M & $296(42 \%)$ \\
F & $65(9.4 \%)$ \\
\hline
\end{tabular}

Table 1 shows the most commonly occurring non-target-like forms in ALEs interlanguage development. Second language learners use mainly the root and the simple present tense forms instead of using the simple past tense forms. This supports of Meisel (1987)'s findings. Meisel noted that language learners from different first language backgrounds acquire the language for referring to the simple past tense events in similar patterns. The first stage in the current study also supports Andersson's (2008) research. Andersson (2008) gives two explanations as to why the simple past is replaced by the simple present tense: first, the fact that the students do not master the inflection of irregular verbs, second, the fact that the students used the Swedish equivalent, so called transfer error (p.19). It is worth mentioning that the same type of errors and the same discussion occurred in Kohlmyr's study (2003, p. 272). In my opinion one explanation of why the root or the simple present were used instead of the simple past tense form by the L2 learners may be that they have not yet recognized how to use the simple past forms. Or they might need to pay more attention to the instructions given, or they need continuous metalinguistic feedback.

\section{Stage Two}

The second most frequent inaccuracy was the use of the target-like spoken forms but in non-target-like written forms; students produced 111 non-target-like forms which represents $11.2 \%$ of the total number of non-target-like forms, (e.g. brook, wint, hapeend, trayed, and colled). Table 2 below shows the proportion of forms which represents the interlanguage development in stage two.

Table 2. Misspelt forms

\begin{tabular}{lll}
\hline Stage & \multicolumn{2}{l}{ The Experimental Group } \\
\hline B & 47 & $(42.3 \%)$ \\
M & 37 & $(33.3 \%)$ \\
F & 27 & $(24.3 \%)$ \\
\hline
\end{tabular}

Table 2 displays the second most frequent non-target-like form in the categorization of ALEs interlanguage development, so-called misspelt forms. This means that second language learners use target-like spoken forms of the simple past tense but they spell the verb forms incorrectly. This stage includes the performance errors produced by the second language learners while acquiring the simple past in English. This type of mistake can be classified as a "one-off" slip rather than a mistake forming part of the second language learners' internal grammar of the language. Although this type occurs in all stages, it is categorized as stage two as the proportional data derived from all non-target-like simple past tense forms produced by all the subjects show that it was far more common than other types of mistakes. 
It is worth mentioning that misspelling of this type might happen due to the differences between the Arabic language and English language in the pronunciation of each letter; silent letters in English (which are not found in the Arabic language) and pronunciation differences between L1 and L2. In general, in learning the Arabic language, learners write what they pronounce with diacritics, while in learning English; learners do not usually pronounce every written letters. For example in Arabic: the words (MEN), (MAAN), (MOON), (MANNA), are all spelled with only two letters: $\mathrm{M}$ and $\mathrm{N}$, but the Arabic diacritics which is put on each of the two letters changes the meaning of the word: e.g.

$M E N$ means (from),

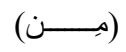

$M A A N$ means (who),

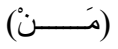

$M O N$ means (give as a gift),

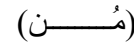

$M A N N A$ means (gave as a gift).

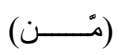

Another example can be $(B A R),(B O R)$, (BER): all three words are written with only two letters in Arabic (B, and $\mathrm{R})$, but the Arabic diacritics used on each letter gives us as users of Arabic different meanings. In other words,

$B A R$ (بَ) (noun) means the vast land where people can have picnic or spend nice time out of the city;

BOR (بُ) (noun) means (wheat);

BER (ب) (noun) means doing favour to other people, and the same pronunciation of that word can be used as a verb in the command form, which means deal with others in a kind way and be helpful to them;

BER (ب) (verb) means do a favour to other people.

In standard Arabic, each word is written as it is pronounced. Hence, this can be one source of misforming/disforming the simple past tense in English. The author can claim here that pronunciation is one of the clear differences between Arabic and English; it is a different orthography, which makes it more difficult for ALEs to spell the simple past tense forms in a target-like way.

\section{Stage three}

The third most frequent non-target-like form was to over-generalize the -ed rule of regular simple past tense form to the irregular simple past tense forms; students produced 63 non-target-like forms which represents $6.4 \%$ of non-target- like usage, (e.g. catched, gived, taked, comed, and leaved). Table 3 below shows the proportion of forms produced by the ALEs in the acquisition of the simple past tense which represents stage F.

Table 3. Overgeneralization of regular forms to irregular forms

\begin{tabular}{ll}
\hline Stage & The Experimental Group \\
\hline B & $9(14 \%)$ \\
M & $19(30 \%)$ \\
F & $35(56 \%)$ \\
\hline
\end{tabular}

Table 3 displays the third most frequent non-target-like form in the categorization of ALEs interlanguage development in the acquisition of simple past tense. Language learners occasionally over-generalize the regular $-e d$ to the irregular simple past forms. It is noticed from table 4.3 above that there is a huge difference between the proportions of the non-target-like simple past related to this stage in the acquisition of the simple past tense. This type of error is classified as occurring at stage four in the study conducted by Meisel (1987), where learners overgeneralize the regular -ed to irregular verbs, and the present perfect instead of the simple past tense.

I can claim that transfer does occur, and the L1 has an impact on L2 learning. It is discussed that transfer can help in the case of closely related languages or of languages with similar typological structures. In the current study, L1 negative transfer occurs because the L1 is very different from the L2.

\section{Stage Four}

The fourth most frequent non-target-like form was to use the verb to be + the simple past tense forms or agent or the past participle forms or the gerund; the students produced 51 non-target-like forms which is $5.1 \%$ of the total number of non-target-like forms, (e.g. were wanted, was came, was went, was started, was broke, were became, and is happening). Table 4 below shows the proportion of the forms representing stage four. 
Table 4. Using verb to be + the simple past/past participle or agent or gerund

\begin{tabular}{|c|c|}
\hline Stage & The Experimental Group \\
\hline $\mathrm{B}$ & $40(78 \%)$ \\
\hline M & $8 \quad(16 \%)$ \\
\hline $\mathrm{F}$ & $(6 \%)$ \\
\hline
\end{tabular}

Table 4 displays the fourth most frequent non-target like form in the categorization of ALEs interlanguage development in the acquisition of the simple past tense. Second language learners use the auxiliary verb to be in conjunction with the simple past tense form and sometimes with the past participle or the gerund form, even though they have not studied the simple past passive or progressive yet. In my opinion this happens due to transfer from the subjects' L1, the equivalent of which is $k a n a$. This verb form is used to describe and narrate events which have happened in the past (see the different ways of describing the past tense in Arabic and how ALEs transfer from L1 to L2 in different ways. This might be considered to constitute a case of negative transfer.

Andersson (2008) explains why the progressive form was used as a substitution of the simple past in the Swedish context (p.20). She explains that the students do not master how or when to use the progressive form and that they use the progressive form whenever they want. It is also worth mentioning that the same phenomenon was found in Kohlmyr's study (2003, pp. 279-280) of Swedish 16-year-old learners of English. This can be evidence of the similarities between Arab learners of English and European learners of English. It is noticed that ALEs use the progressive forms as a substitution for the simple past tense forms.

\section{Stage Five}

The fifth most frequent non-target-like form resulted from the errors in number concord, using was and were alternatively in a non-target-like way; students produced 49 non-target-like forms which is $5 \%$ of the total number of non-target-like forms, (e.g. they was, he were, she were, the woman were, and the driver were). Table 5 below shows the proportion of the forms representing the lack of appropriate number and person concord. It is worth pointing out that these forms are not considered errors in using/acquiring the simple past, but mistakes in agreement in number and person. These mistakes could be corrected when L2 learners' attention is drawn to it through metalinguistic feedback provided by the teacher. These simple past tense forms have been categorized in the interlanguage development stages as "Number/person concord" for the purpose of the study, one of which is to find out how to improve language learners' written accuracy.

Table 5. Number/person concord of was/were

\begin{tabular}{ll}
\hline Stage & The Experimental Group \\
\hline B & $22(45 \%)$ \\
M & $17(35 \%)$ \\
F & $10(20 \%)$ \\
\hline
\end{tabular}

Table 5 above displays the fifth most frequent non-target-like form in the categorization of ALEs interlanguage development in the acquisition of the simple past tense. Second language learners misselect the target-like verb. Some of them use was for the plural, and others use were for singular (e.g. the driver and the woman was.., the girl were...... Laila and Mona was......).

\section{Stage Six}

The sixth most frequent non-target-like form was to use blended forms. These were of two types: the first type of blended forms is using the infinitive to + the simple past tense forms or the past participle forms, while the second type of blended forms is using "have" or "has" + the simple past tense forms or the past participle forms; students produced 22 non-target-like forms which is $2.2 \%$ of the total number of non-target-like forms, type one: (e.g. to went, to called, to moved, and to seen) and type two: (e.g. has went, have helped, and has arrived).

Lightbown and Spada (2006) mention that a number of studies show that many errors can be explained better in terms of learners' developing knowledge of the structure of the target language rather than in terms of an attempt to transfer patterns of their first language (p.79). Their view seems to be contradicted by the blended forms produced by the ALEs, illustrated in the sixth category described below. Table 6 below shows the proportion of the forms representing the first type of the blended forms. 
Table 6. Using to + the simple past tense forms or the past participle forms

\begin{tabular}{ll}
\hline Stage & The Experimental Group \\
\hline B & $9(60 \%)$ \\
M & $3(20 \%)$ \\
F & $3(20 \%)$ \\
\hline
\end{tabular}

Table 6 above shows the first type of blended form produced by the subjects in the experiment. The learners used to + the simple past tense or the past participle, e.g. to visited, to came, to ran, and to called. It is likely that this is again transfer from Arabic, where the equivalent of to "ann", is commonly used in narrating stories. This is again an instance of negative transfer and, though these forms were infrequent, their existence undermines a strong form of the argument presented by Lightbown and Spada.

Another type of blended forms includes the use have or has + the simple past tense forms or the past participle forms. Table 7 below shows the proportion of the forms used by ALEs representing the second type of the blended forms.

Table 7. Using have or has + the simple past tense forms or the past participle forms

\begin{tabular}{ll}
\hline Stage & The Experimental Group \\
\hline B & $7(100 \%)$ \\
M & $0(00 \%)$ \\
F & $0(00 \%)$ \\
\hline
\end{tabular}

Table 7 above shows the second type of the blended forms produced by subjects in the experiment. In an early interlanguage stage students use the blended forms. ALEs use have or has + the past participle or the simple past tense forms instead of the simple past tense forms although they had not yet been presented with the present perfect or the past passive. One explanation for this phenomenon, as previously mentioned, may be that they may have read or learnt these forms somewhere else. To find out if this was the case, I checked their school course book and found that they had studied the present perfect tense form in the first four units in semester one. This was then followed by studying present and past progressive in the second semester. I think that producing the present perfect as a substitution for the simple past tense forms at this stage can be evidence for the overgeneralization of the category of present perfect on the simple past tense forms and more than likely due to transfer from Arabic. I can claim that this overgeneralization has a relationship with L1 because Arabic has only four fixed tense forms in which learners use a fixed form for each tense - each form must match with the subject used with the target tense- present, past, future, and order, and there is no present perfect in Arabic language (e.g.

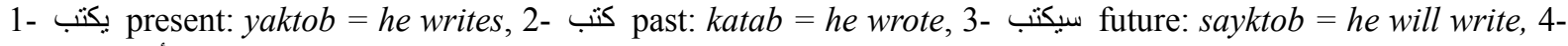
Order: أكتب oktob =write). Though Arabic has no has/have + past participle form (which students might transfer), students might think that there is only ONE form for the past (based on their experience of Arabic) and, having learnt the present perfect, assume that that is the only way that the past is expressed in English.

\section{Stage Seven}

The seventh most frequent non-target-like form was to over-generalize a sub-rule of the irregular simple past tense forms to other irregular simple past tense verbs; students produced 3 non-target-like forms which represent $0.03 \%$ of the total number of non-target-like forms, (e.g. brang, and stold). Table 8 below shows the proportion of the forms representing the least frequent non-target like form in the acquisition of the simple past tense forms.

Table 8. Over-generalizing a sub-rule of irregular simple past

\begin{tabular}{ll}
\hline Stage & The Experimental Group \\
\hline $\mathrm{B}$ & $3(100 \%)$ \\
$\mathrm{M}$ & $0(00 \%)$ \\
$\mathrm{F}$ & $0(00 \%)$ \\
\hline
\end{tabular}

Table 8 above displays the least frequent non-target-like form in the categorization of ALEs interlanguage development in the acquisition of the simple past tense forms. Second language learners very rarely 
overgeneralize a sub-rule of the irregular simple past to other simple past verbs. This provides very limited support for a U-shaped learning model of second language acquisition, at least amongst ALEs at the pre-intermediate/intermediate level.

\section{Discussion}

As is shown above, some interlanguage forms which appear in the current study are similar to those found in other studies investigating the stages undergone in the acquisition of the simple past tense in English, and thereby support these findings. Yet, other studies do not match with, or support, the current study's findings. In other words, some interlanguage phenomena found in the current study are not found in other studies, such as type four where Arab learners of English use the verb to be + the simple past tense form, agent, or the past participle, or the gerund, taking into account that they have not studied the simple past passive or present perfect in the IWP. I think this happens due to the use of كان "kana" in Arabic to describe and narrate past events.

The current study reveals that negative transfer does occur from Arabic to English due to the differences between the languages. The analysis of the learners' non-target-like forms reveals that $11.2 \%$ of the non-target-like forms were as a result of the differences in pronunciation between $\mathrm{L} 1$ and $\mathrm{L} 2$. The analysis also reveals that $5.1 \%$ of the non-target-like forms were produced due to L1 interference (using verb to be + simple past tense form), and also $2.2 \%$ of the non-target-like forms were due the L1 negative transfer (using to + simple past tense forms) and also due to the $\mathrm{L} 2$ negative transfer ( using have, has + simple past tense forms).

Another difference between the current study and other studies in categorizing the interlanguage phenomena which arise in the acquisition of the simple past forms is using blended forms, i.e. using infinitive to + the simple past tense form or the past participle by ALEs. This related specifically to Arab learners of English, because the equivalent of to is also used in narrating stories in Arabic. Based on the above, the influence of L1 can be noticed in acquiring L2 specifically during the acquisition of the simple past tense in English.

It is worth mentioning that categorizing the interlanguage stages followed by ALEs in their acquisition of the simple past tense does not mean that these stages appear in isolation. It is difficult to identify a clear cut-off point between each stage and another. It can be claimed that they are all related to each other. It can only be gauged in a statistical way: there is proportionately more of one type than another as they go along. In other words, ALEs do not leave one stage behind when they enter another stage. Sometimes advanced learners slip back to an earlier stage. Lightbown and Spada (2006) mention that the progress achieved by second language learners to a higher stage in interlanguage does not always mean that learners produce fewer errors (p.93). Overgeneralization of the regular -ed form to irregular forms is a case in point. This is progress by comparison with simply producing the uninflected base form - and students might be praised for having the right idea but alerted to the fact that, in this case, the verb is irregular so their hypothesis (based on a number of regular verbs) does not apply.

In spite of the great variety in the subjects' L1 and other studies with different language backgrounds with regard to acquiring the simple past tense in English, the similarities of the earliest interlanguage stages of second language acquisition were clearly found.

Coding and categorizing the interlanguage stages in acquiring the simple past differs from one researcher to another. In what follows, I will shed some light on some of these studies and how they are similar to, or different from, the findings of the current study. First, I will talk about categorization then I will talk about coding.

First, Meisel (1987) noted that adding -ing occurs at the second stage of simple past acquisition in his study. The second result of Meisel's study was that all learners in all groups of the study produced a similar number of non-target-like past time activity verbs. Then, some other studies comment on second language learners' use of the progressive forms instead of the simple past tense forms as they acquire the simple past tense in English, (Bardovi-Harlig 1998, 2000; Bardovi-Harlig and Reynolds 1995; Robinson 1995) stating that all progressive forms whether in present or past progressive or even without an auxiliary verb produced by the learners, associated robustly with activity verbs. This association strengthens as proficiency increases.

Finally, McDonough (2007) comments that while learners use progressive forms in past tense contexts often in a non-target-like fashion, particularly for progressive forms, this represents development as learners' reliance on the present and base forms decreases and the learners begin to distinguish lexical verbs classes by using progressive forms (p.337). What happened in the current study is that a few high level learners used progressive forms in stage $\mathrm{B}$, but this decreased gradually in the following two stages $\mathrm{M}$ and $\mathrm{F}$.

Previous studies have looked at past tense morphemes and tried to figure out the order in which these morphemes are acquired with respect to the semantics of the verbs in question. These studies refer to Aspect Hypothesis, such as Antinucci \& Miller (1976), Andersen (1986, 1991), and Andersen \& Shirai (1996). 
In his empirical study, Andersen (1991) postulated a sequence of developmental stages. The development of the simple past tense seemed to spread from achievement verbs to accomplishment verbs to activities verbs and finally to states verbs. Similarly, Bardovi-Harlig (2000) found that second language learners are more likely to mark past tense on some verbs than on others. She comments that the differences appear to be due to the lexical aspect. In other words, learners apply and mark the simple past tense on verbs expressing accomplishments and achievements before verbs expressing states. In the current study, the lexical aspect of the verbs produced by the subjects of the study has not been investigated. This is due to the fact that the verbs used in the picture-stories are exclusively activity verbs. It was thus impossible to test hypotheses on order of acquisition in relation to lexical aspects such as this.

As it is mentioned above, Lightbown and Spada (2006) argued that sometimes language acquisition is reflected in a decrease in the use of a correct form that was based on rote memorization or chunk learning. They add that an increase in error may be an indication of progress, mentioning that, like first language learners, second language learners usually learn the irregular past tense forms before they learn to apply the regular simple past $-e d$ marker. My findings support this but it is not supported by those of Ellis (1987a), Ellis \& Barkhuizen (2005), or Brown (1998) who concluded the opposite.

McDonough (2007) followed previous research studies such as those conducted by Bardovi-Harlig (1998), and Lardiere (1998), in excluding ambiguous contexts from the analysis. In McDonough's study, the coding of the learners' activity verbs in past time contexts were in terms of their grammatical forms as simple past morphology -ed supplied or absent. One of the results of McDonough's study is that students in all groups - no feed group, clarification request group, and recast group - tended to use the simple present tense and the base forms with their past time activity verbs and rarely produced progressive forms. This result supports the current study which reveals that ALEs start forming the simple past tense forms in English by using the root or the simple present tense forms instead of the simple past tense form. My current findings also echo McDonough with respect to there being fewer examples of using the progressive forms produced by the subjects of the study as they acquire the simple past tense.

The subjects of the current study in the context of their picture-story narrative did not produce all types of verbs mentioned by Wulff et al. (2009), Salaberry (2005), and Bardovi-Harlig $(1998,2000)$, as the verbs used in the picture-stories are exclusively activity verbs.

By evaluating the interlanguage grammar development stages in the acquisition of the simple past tense in the ALEs' context mentioned above, the similarities between the interlanguage features which appear in these studies and my own, are numerous. It is also noticed that the differences which occur might be due to the nature of Arabic grammar and its influence in SLA as is previously explained.

\section{Conclusion}

As a result of the analyses and the discussion presented above, it is concluded that the interlanguage stages cannot be separated, they do not appear in isolation, and they are connected with each other. The linguistic data received from the teacher - the first input - worked in the learners' mind and their internalized grammar began to develop. The learners then attempted to produce the language narrating the picture-story with some or many non-target-like forms. Students were exposed to further input - intake - and then they attempted to produce the target-like forms based on the metalinguistic feedback received. The analysis of the data suggested that ALEs go through seven interlanguage stages in the acquisition of the simple past tense forms. These are listed below but they are not necessarily in sequential order; there is a great deal of fluctuation in learner behaviour which makes it difficult to establish an implicational hierarchy:

The students' non-target-like forms were categorized into seven types as follows:

1- Use the root or the simple present forms

(E.g. go, come, stay, calls, help)

2- Use spoken target-like forms but written non-target-like written forms

(E.g. brook, wint, hapeend, trayed, colled)

3- Overgeneralizing the -ed to irregular verbs

(E.g. catched, gived, taked, comed, leaved)

4- Use verb to $B e$ + the simple past, agent, the past participle or the gerund etc.

(E.g. were wanted, was came, was started, was broke, were became, is happening) 
5- Number concord errors in the target-like verb forms

(E.g. they was, he were, she were, the woman were, the driver were)

6- Use blended forms

A- Use have, has + the simple past or the past participle

(E.g. has went, have helped, has arrived)

B- Use infinitive to + the past simple or the past participle

(E.g. to went, to called, to moved, to seen)

7- Overgeneralizing a sub-rule of irregular simple past on other irregular simple past or regular simple past

(E.g. brang, stold, foul)

The results of the current study provide evidence that second language learners of English generally acquire/learn the irregular simple past tense forms before the regular simple past tense forms. This occurs despite the fact that in their "first" learning of the simple past (as they were already pre-intermediate to intermediate students when they began the course), teachers expected to teach the "regular" formation in the presentation of the simple past tense.

\section{References}

Andersen, R. (1986). The development of verbal morphology in Spanish a second language. In J. Meisel (ed.), Acquisition of Language. Frankfurt: Vervuert. pp. 115-138.

Andersen, R., \& Shirai, Y. (1996). The primacy of aspect in first and second language acquisition: the pidgin-creole connection. In W. Ritchie, \& Bhatia, T. (eds.), Handbook of Second Language Acquisition. San Diego, Calif: Academic Press. pp. 527-570.

Andersson, L. (2008). Error made in time and tense: An investigation of errors made in time and tense in composition writing by 9th grade learners of English in Sweden: Gotebrag University, Department of English, and Linguistic C-essay. Interdisciplinary paper.

Antinucci, F., \& Miller, R. (1976). How children talk about what happened. Journal of Child language, 3, 167-189. http://dx.doi.org/10.1017/S0305000900001434

Bardovi-Harlig, K. (1998). Narrative structure and lexical aspect: conspiring factors in the second language acquisition of tense-aspect morphology. Studies in Second Language Acquisition, 20(4), 471-508.

Bardovi-Harlig, K. (2000). Tense and Aspect in Second Language Acquisition: Form, Meaning, and Use. Oxford: Blackwell.

Bardovi-Harlig, K., \& Reynolds, D. (1995). The role of lexical aspect in the acquisition of tense and aspect. TESOL Quarterly, 29(1), 107-31. http://dx.doi.org/10.2307/3587807

Baroudy, I. (2008). Process writing: Successful and Unsuccessful Writers; Discovering Writing Behaviours. International Journal of English Studies, 8(2), 43-63.

Brown, R. (1973). A First Language. Cambridge, MA: Harvard University Press.

Brown, H. D. (1987). Principles of language learning and teaching (2nd ed.). Englewood Cliffs. N.J.: Prentice-Hall, Inc.

Brown, P. (1998). Children's first verbs in Tzeltal: evidence for an early verb category. In Elena Lieven (ed.), Special edition of Linguistics, 36(4), pp. 713-53.

Collins, L. (2002). The roles of L1 influence and lexical aspect in the acquisition of temporal morphology. Language learning, 52(1), 43-94. http://dx.doi.org/10.1111/1467-9922.00177

DeVilliers, P., \& DeVilliers, J. (1973). A cross-sectional study of the acquisition of grammatical morphemes in child speech. Journal of Psycholinguistics Research, 2, 267-278. http://dx.doi.org/10.1007/BF01067106

Dickens, P., \& Woods, E. (1988). Some criteria for the development of communicative grammar tasks. TESOL Quarterly, 22(4), 194-195.

Doughty, C., \& Varela, E. (1998). Communicative focus on form. In C. Doughty, \& Williams, J. (eds.) (1998), Focus on Form in Classroom Second language Acquisition. Cambridge: Cambridge University Press. pp. 114-138.

Ellis, R. (1987a). Interlanguage variability in narrative discourse: style shifting in the use of the past tense. 
Studies in Second Language Acquisition, 9, 1-20. http://dx.doi.org/10.1017/S0272263100006483

Ellis, R. (Ed.). (1987b). Second Language Acquisition in Context. London: Prentice-Hall.

Ellis, R., \& Barkhuizen, G. (2005). Analyzing Learner Language. Oxford: Oxford University Press.

Frawley, W., \& Lantolf, J. (1985). Second Language discourse: a Vygotskian perspective. Applied Linguistics, 6, 19-44. http://dx.doi.org/10.1093/applin/6.1.19

Fuller, J., \& Gundel, J. (1987). Topic prominence in Interlanguage. Language Learning, 37, 1-18. http://dx.doi.org/10.1111/j.1467-1770.1968.tb01310.x

Gao, H. (2001). The physical foundation of the patterning of physical action verbs. Lund University Press.

Harmer, J. (1991). The Practice of English Language Teaching. London: Longman.

Hopper, P. J. (1982). Aspect between discourse and grammar: an introductory essay for the volume. In J. Paul, Hopper (ed.), Tense-aspect: Between Semantics and Pragmatics. Amsterdam-Philadelphia: Benjamins. pp. 3-18.

Housen, A. (1995). It's about time. Unpublished doctoral dissertation. Vrije Universiteit, Brussels, Belgium.

Hymes, D. (1972). Models of the Interaction of language and social life. In J. Gumperz, \& D. Hymes (eds.), Directions in sociolinguistics: ethnography of communication. New York, N Y: Holt, Rinehert \& Winston. pp. 35-71.

Ismail, S. (2010). ESP Students' Views of ESL Grammar Learning. Journal of Language Studies, 10(3), 143-156.

Klein, W. (1986). Second Language Acquisition. Cambridge: Cambridge University Press. http://dx.doi.org/10.1017/CBO9780511815058

Kohlmyr, P. (2003). To Err Is Human....: An investigation of grammatical errors in Swedish 16-year-old learners' written production in English. Goteborg Universitet, Goteborg.

Larsen-Freeman, D., \& Long, M. H. (1991). An Introduction to Second Language acquisition Research. Harlow: Longman.

Leech, G., \& Svartvik, J. (1982). A communicative grammar of English. London: Longman.

Lightbown, P., \& Spada, N. (1997). Learning English as a second language in a special school in Quebec. Canadian Modern Language Review, 53(2), 315-355.

Lightbown, P., \& Spada, N. (2006). How Languages are Learned (Second edition). Oxford: Oxford University Press.

Ling, C. X., \& Marinov, M. (1993). Answering the connectionist challenge: a symbolic model of learning the past tenses of English verbs. Cognition, 49(3), 235-290. http://dx.doi.org/10.1016/0010-0277(93)90006-H

MacWhinney, B., \& Leinbach, J. (1991). Implementations are not conceptualizations: revising the verb learning model. Cognition, 40, 121-157. (154 N.A. Taatgen, J. R. Anderson / Cognition 86, (2002), pp. 123-155)

McDonald, J., \& Roussel, C. (2010). Past tense grammaticality judgment and production in non-native and stressed native English speakers: Department of psychology, Louisiana University. Bilingualism: Language and Cognition Volume, 13(4), 429-448. http://dx.doi.org/10.1017/S1366728909990599

McDonough, K. (2007). Interactional feedback and the emergence of simple past activity verbs in L2 English. In A. Mackey (ed.), Conversational Interaction in Second Language Acquisition: A Collection of Empirical Studies. Oxford: Oxford University Press. pp. 323-338.

Meisel, J. M. (1987). Reference to past events and actions in the development of natural second language acquisition. In C. Pfaff (ed.), First and Second Language Processes. Cambridge MA: Newbury House. pp. 206-224.

Pienemann, M. (2005). Cross-linguistic Aspects of Processability Theory. Amsterdam: Benjamins.

Pinker, S., \& Prince, A. (1988). On language and connectionism: Analysis of a parallel distributed processing model of language acquisition. Cognition, 28, 73-193. http://dx.doi.org/10.1016/0010-0277(88)90032-7

Plunkett, K., \& Juola, P. (1999). A connectionist model of English past tense and plural morphology. Cognitive Science, 23, 463-490. http://dx.doi.org/10.1207/s15516709cog2304_4

Plunkett, K., \& Marchman, V. (1991). U-shaped learning and frequency effects in a multi-layered perception: $\begin{array}{lllll}\text { implications for child language acquisition. Cognition, 38, } & \text { 43-102. }\end{array}$ 
http://dx.doi.org/10.1016/0010-0277(91)90022-V

Plunkett, K., \& Marchman, V. (1993). From rote learning to system building: acquiring verb morphology in children and connectionist nets. Cognition, 48, 21-69. http://dx.doi.org/10.1016/0010-0277(93)90057-3

Quirk, R., Greenbaum, S., Leech, G., \& Svartvik, J. (1985). A comprehensive Grammar of the English language. Harlow/New York: Longman.

Ramadani, A. (2009). The students' mastery in using simple past tense of faculty of letters. Gunadarma University: A paper Undergraduate Thesis. English Language Department. Jakarta. August, 2009.

Rumelhart, D. E., \& McClelland, J. L. (1986). On learning the past tense of English verbs. In J. L. McClelland, \& D. E. Rumelhart (eds.), Parallel distributed processing: explorations in the microstructure of cognition. Cambridge, MA: MIT Press. pp. 216-271.

Salaberry, M. R. (1999). Procedural vocabulary: Lexical signalling of conceptual relations in the development of past tense verbal morphology in classroom L2 Spanish. Applied Linguistics, 20, 151-78. http://dx.doi.org/10.1093/applin/20.2.151

Salaberry, M. R. (2003). Assessing the effect of lexical aspect and grounding on the acquisition of L2 Spanish past tense morphology among L1 English speakers. Bilingualism, Language and Cognition, 14(2), 184-202. http://dx.doi.org/10.1017/S1366728910000052

Salaberry, M. R. (2005). Bridging the gap between theoretical and empirical findings in the analysis of tense-aspect data in L2 acquisition. (co-authored with Dalila Ayoun). In D. Ayoun, \& Salaberry, M. R. (eds.), Tense and Aspect in the Romance Languages: Theoretical and applied perspectives. Amsterdam/Philadelphia: Benjamins. pp. 253-281.

Salaberry, R., \& Shirai, Y. (2002). The L2 acquisition of tense-aspect morphology. Amsterdam/Philadelphia: Benjamins.

Vendler, Z. (1967). Verbs and times. In Z. Vendler (ed.), Linguistics and Philosophy. Ithaca, N.Y.: Cornell University Press. Reprinted from Philosophical Review (1957), 66/1, pp. 143-60.

Vet, C., \& Carl, V. (1994). Tense and Aspect in Discourse. Berlin: Mount de Gruyter. http://dx.doi.org/10.1515/9783110902617

Walvoord, B., \& Fassler, E. (1985). Writing, Strategies for all disciplines. London: Prentice Hall International, Inc.

Wulff, S., Ellis, N. C., Romer, U., Bardovi-Harlig, K., \& LeBlanc, C. (2009). The acquisition of Tense - Aspect: Converging Evidence From Corpora and Telicity Ratings. The Modern Language Journal, 93(iii), 354-369. http://dx.doi.org/10.1111/j.1540-4781.2009.00895.x

Yap, D., \& Alsagoff, L. (2005). Error in tense and aspect in compositions of Secondary School students in Singapore. Department of English language and literature, NIE, NTV. 